\title{
METHODS OF HUMIDITYANALYSIS IN TRANSFORMER OIL
}

To prevent failure states of transformer, we performed different types of measurements. We made measurements of a frequency dependence of capacity of test transformer immersed in tank with transformer oil. The capacity illustrates a momentary state of the measured equipment and its variations to indicate the changes in the transformer oil. Water content in the transformer oil causes deterioration of its insulation and, finally, thermal defect of solid insulation.

Keywords: humidity, transformer, insulation resistance, dissipation factor

\section{Introduction}

The state of new insulation in operation mostly deteriorates due to surface contamination of insulators and insulation, their moistening and ageing. If no measures are taken in time so as to avoid this degradation, the situation usually results in damage of insulator and consequently in stop of an electrical device. Insulation state of important electrical devices, such as transmission transformer which bring huge economic cost due to each stop in operation, needs to be checked regularly $[1,2]$.

Water content in the transformer oil causes deterioration of its insulation and thermal defect of solid insulation. Dielectric warming can be so high that the temperature increase is out of control and transformer becomes dangerous for its surrounding.

\section{Analysis of humidity by measuring insulation resistance}

The oldest and the easiest method of inspecting the state of insulators is by means of an insulation resistance measurement. The main disadvantage of this method is that the insulation resistance does not only depend on the state of insulation but also on its type and dimensions. Therefore, the insulation resistance method can be used to evaluate the state of insulation of an electric device only on the basis of previous experience with the same insulation on a similar device. Moreover, this method enables to identify even small insulation degradation, if it passes through an insulation layer e.g. oil - paper, but it cannot identify whether the degradation is on the side of oil or paper, which is its next drawback.

The time development of resistance can be measured (Fig.1) by the MEGGER MIT510 insulation tester, which provides direct reading of the insulation resistance in ohms regardless of the test DC voltage selected. Resistance of insulation is calculated applying Ohm's Law by measuring the resultant current at the given DC voltage. Unfortunately, more than one current flows, which tends to complicate matters. The main components of resultant current are the capacitance charging current, the absorption (or polarization) current and the conduction or leakage current. The capacitive current is initially large, but goes to zero as the test piece is charged. The absorption current is caused by charges in the insulation material moving under the effect of the electric field absorption (polarization). Conduction current is stabilized after few seconds of application of test voltage while absorption current is decreased with time. The conduction current is greatly affected by humidity or contamination in the insulation.

Utilizing this knowledge for evaluation of insulation state does not require determining full time dependence of the resistance

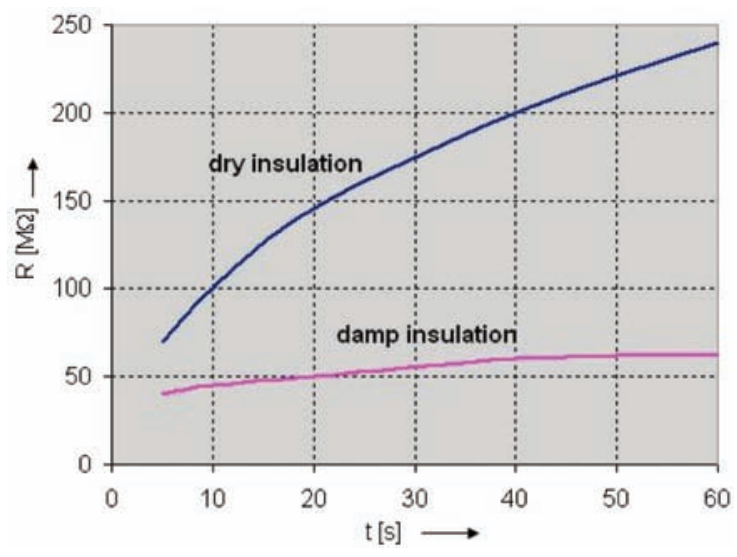

Fig. 1 Typical time dependence of the insulation resistance

\footnotetext{
* Miroslav Gutten ${ }^{1}$, Jozef Kudelcik ${ }^{2}$

${ }^{1}$ Department of Measurements and Applied Electrical Engineering, University of Zilina, Slovakia, E-mail: gutten@fel.uniza.sk

${ }^{2}$ Department of Physics, University of Zilina, Slovakia
} 
(current). It is enough to determine a value of the resistance (current) in two different moments from the time of connection to test DC voltage. The ratio of these two values defines the state of insulation and is called the polarization index. The polarization index is positive number (a non-dimensional parameter) and it does not depend on dimension of insulation. In the USA it is defined as the one-minute reading divided into ten-minute reading to provide a ratio, in the EU the times are 15 and 60 seconds.

To better illustrate the change in values of polarization index, it needs to be expressed by both types of currents - absorption $i_{a}$ and conduction $i_{c}$.

$$
p_{i}=\frac{R_{60}}{R_{15}}=\frac{i_{a 15}+i_{c}}{i_{a 60}+i_{c}}
$$

Contaminated and humidity insulation is mainly determined by $i_{c}$, therefore numerator and denominator in eq. (1) are very close values and their ration tends to 1 . On the other hand, dry and clean insulation, which is in good condition, has a very low conduction current and the time dependence on the absorption current $i_{a}$ is dominant. Thus, the fraction value is noticeably higher than 1 . Values above 2 indicate that the insulation conditions are all right.

The next advancement of the measurement of polarization index against isolation resistance is the great advantage of its being independent on temperature. So we don't need temperature stabilization during the whole measurement. Of course, the temperature cannot be changed during a single measurement.

\section{Humidity analysis by the measurement of dissipation factor and capacity}

The measurements of a dissipation factor $\operatorname{tg}(\delta)$ and capacities of transformer windings are used for additional determination of the insulation quality as a whole or only of some parts of the transformer. The value of the dissipation factor indicates the presence of polar and ion compounds in oil and it also determines the ageing of oil. The degree of oil humidity (water content in oil) can be measured by temperature dependence of the dissipation factor [3].

The next method for determination of the degree of oil humidity (to $10 \mathrm{kHz}$ - Fig. 2) is a frequency dependence on the capacity of a transformer. In damp isolation, the absorption current is negligible to leakage current, which is independent on frequency. The stage of insulation can be determined as the ratio of capacities at two different frequencies. Frequencies of 2 and $50 \mathrm{~Hz}$ are used in the case of a class A transformer. The values of the ratio $C_{2} / C_{50}$ before dehydration are in the range between 1.3 and 2.3 and after dehydration are around 1.2.

The next method of the determination of oil humidity was the measurement of the value of capacity at various temperatures. The capacity is the function of the absorption processes, which are characterized by their time constants and distribution of absorp- tion charges. This method is a basis for the determination of the ratio: $\left(C_{75}-C_{20}\right) / C_{80}$, where $C_{20}$ and $C_{75}$ (or $C_{80}$ ) are capacities at 20 and $75^{\circ} \mathrm{C}$ (or $80{ }^{\circ} \mathrm{C}$ ). This method was in practice substituted by the previous method $\left(C_{2} / C_{50}\right)$ due to problems with defined temperature of transformers.

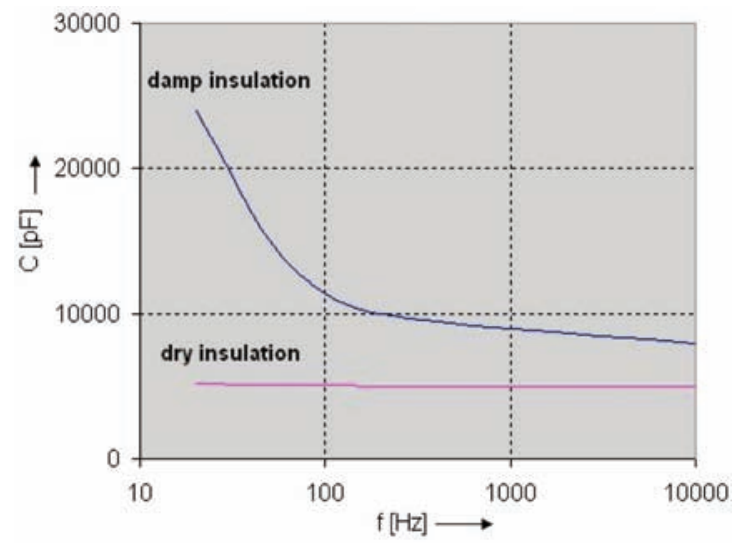

Fig. 2 The frequency change in capacities of dry and damp insulation

\section{Description of experimental measurements}

The test transformer (60 VA, $220 / 52 \mathrm{~V})$ immersed in a tank with transformer oil ITO 100 is provided as an example of safety and reliability inspection of the transformer based on insulation humidity (Fig. 3). We changed water content in the transformer oil and temperature of this transformer oil. We measured capacities as functions of the oil temperature, the applied frequency (to $10 \mathrm{kHz}$ ) and the oil humidity. The automatic measurements of capacities were made using RLC meter and computer program. All the measured values were plotted using Excel. The results were compared with the value of the insulation resistance.

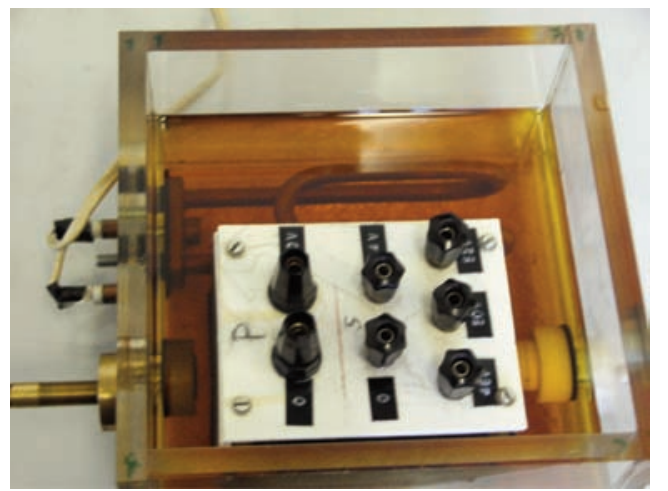

Fig. 3 Test transformer (60 VA, 220/52 V) immersed in tank with transformer oil with heating apparatus

The automatic RLC meter was used to measure the dependence of capacity on frequency. The component measurement is based on the current and voltage technique [4, 5]. Duration of 
each measurement cycle was approximately 0.5 seconds. AC measurements for one frequency consist of seven single measurements, during which the following values were measured: $V_{p}, V_{q}$, $I_{p}$ and $I_{q}$. The measured values are displayed on a phase diagram (Fig. 4) and the phase relation between $I$ and $V$ happens to be a load inductance. The microprocessor uses the measured values to calculate the equivalent series resistance $R_{s}$, the equivalent series reactance $X_{s}(2)$ and the quality factor $Q=X_{s} / R_{s}$ of the measured component. From previous values it determined - using equations [4] - the dominant parameters (resistance, capacitance, or inductance) of the measured transformer and displays it together with the equivalent circuit symbol.

The series resistance and reactance are calculated from these components

$$
R_{s}=\frac{V_{p} I_{p}+V_{q} I_{q}}{I_{p}^{2}+I_{q}^{2}} \quad X_{s}=\frac{V_{q} I_{p}+V_{p} I_{q}}{I_{p}^{2}+I_{q}^{2}}
$$

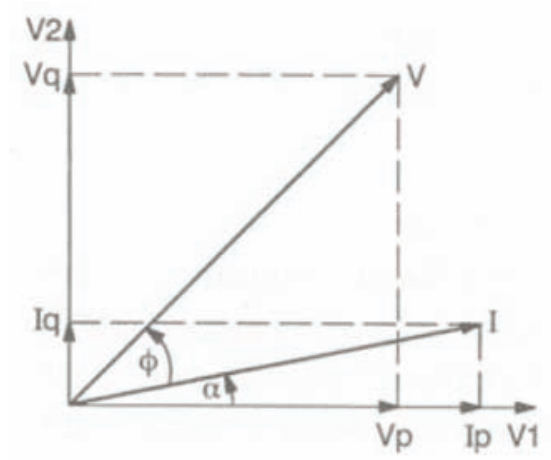

Fig. 4 Phase diagram of measured values

\section{Results of the measurements}

The state of insulation was measured for moisture content of $0 \%, 0.05 \%, 0.15 \%$ and $0.25 \%$ in transformer oil (Fig. 5, [6]). At moisture content $0.05 \%$, we already experienced a significant change in waveform upwards (increase in humidity - Fig. 5). The aim of this experiment was to verify the relation between the increase of oil humidity and capacity-frequency characteristics (see Fig. 2). Based on the measurements, we proved correctness, reliability and high sensitivity of the method for determining humidity in the transformer.

In the second step of measurements, we measured frequency dependence of capacity for various oil temperature (see Fig. 6). The measurements were made at these temperatures of the transformer oil: $25,35,45,55,65$ and $75^{\circ} \mathrm{C}$. The experimental measured values verified the connection between the increase of temperature and the change of frequency development of capacity (see Fig. 6). From the measurements also follows that the capacity is the function of the absorption processes and charges, which are characterized by their time constants dependent on temperature of the system.

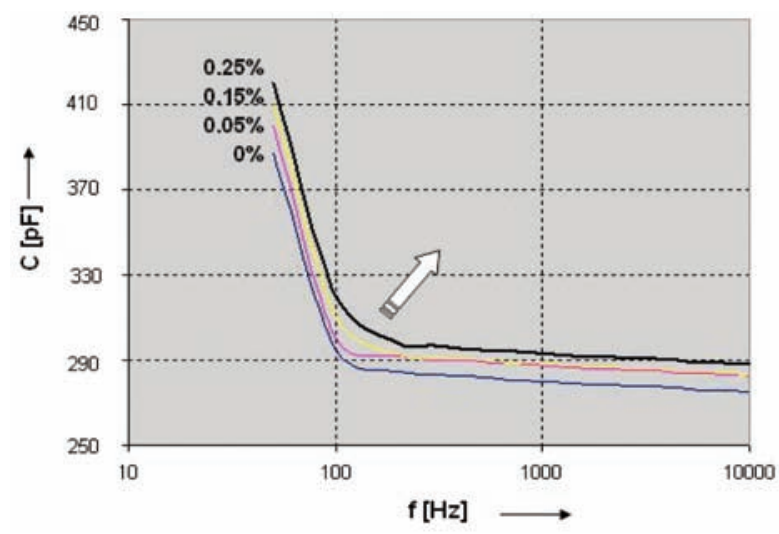

Fig. 5 The frequency dependence of capacity as function for moisture content of $0 \%, 0.05 \%, 0.15 \%$ and $0.25 \%$ in transformer oil (waveforms increase with moisture content)

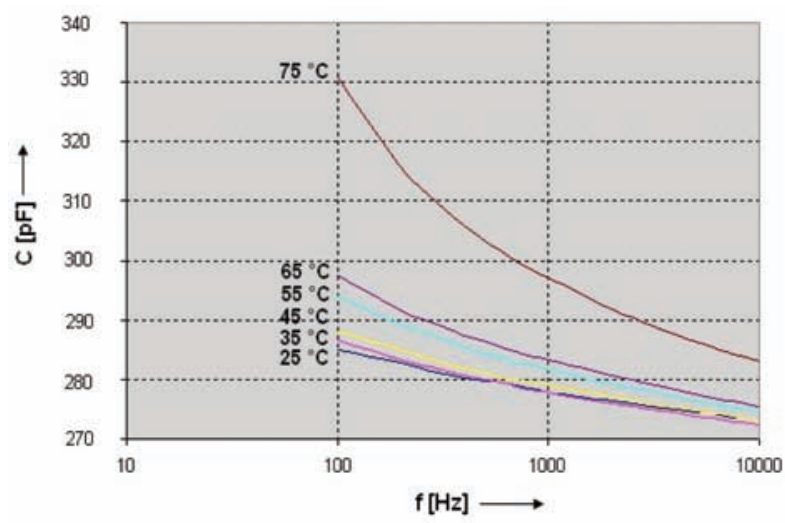

Fig. 6 The frequency dependence of capacity as function of oil temperature

In the last step we measured temperature dependence of the dissipation factor $\operatorname{tg}(\delta)$ at $100 \mathrm{~Hz}$ (Fig. 7). The ranges of temperatures were determined by normal stages of the transformer $\left(20^{\circ} \mathrm{C}\right.$ to $75{ }^{\circ} \mathrm{C}$ ) and the temperature $85^{\circ} \mathrm{C}$ (transformer thermal overload, the polarization index is close to 1). The dissipation factor increases with temperature and at the temperature around $50{ }^{\circ} \mathrm{C}$ there is a visible step. These results were compared with the values of insulating resistances at $15 \mathrm{~s}$ and $60 \mathrm{~s}$ (R15 a R60 - Fig. 7). The insulating resistances R15 and R60 decrease with temperature and at temperature over $75^{\circ} \mathrm{C}$ resistance values are very similar. In the range of temperatures $40-60{ }^{\circ} \mathrm{C}$ there can be seen steps on the waveforms - represented by a dash circle. Resultant similarities between insulation resistances and dissipation factor show that we verified the connection between both these methods.

\section{Conclusion}

Based on the measurements we proved correctness and high sensitivity of both methods for determination of transformer oil 


\section{COMMNICOIIONS}

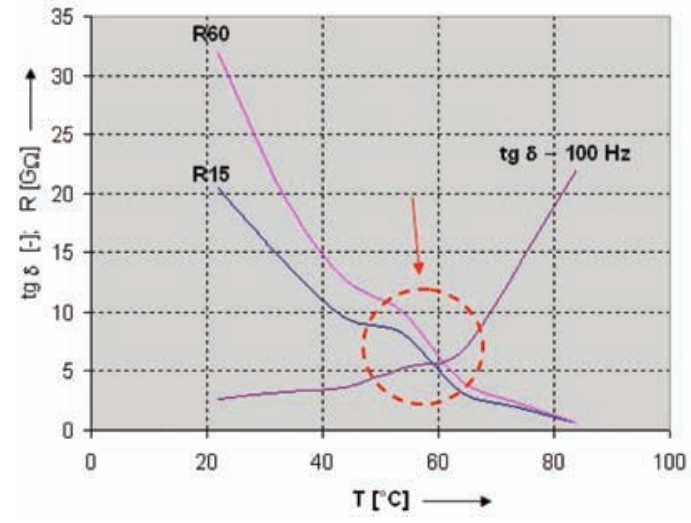

Fig. 7 The temperature dependence of dissipation factor $\operatorname{tg}(\delta), R 15$ and $R 60$. humidity in the transformer, i.e. the frequency monitoring of capacity or $\operatorname{tg}(\delta)$ to $10 \mathrm{kHz}$. These methods can be utilized to determine an insulation state during a short term layoff of the transformer and thus increase its reliability and safety.

\section{Acknowledgments}

This work was supported by the Grant Agency VEGA from the Ministry of Education of the Slovak Republic under contract $1 / 0515 / 09$ and $1 / 0548 / 09$.

\section{References}

[1] GUTTEN, M.: Diagnostic and Monitoring of Power Transformers, Proc. of $5^{\text {th }}$ International Conference Elektro 2004, Zilina 2004, pp. 300-301,

[2] MARTON, K., KURIMSKY, J., BALOGH, J.: Partial Discharges in the Diagnostics of Transformers (in Slovak), In: Monitorovacie a diagnostické systémy transformátorov, EDIS ZU, Zilina, 2007, pp. 23-45,

[3] ARTBAUER, J., SEDOVIC, J., ADAMEC, V.: Insulators and insulations (in Slovak), ALFA, Bratislava, 1969, ,

[4] Manual Fluke 6306 - RLC meter,

[5] http://assets.fluke.com/images/products/fpm/bench_in-struments/ds_rcl_6304_6.pdf

[6] GUTTEN, M., KUDELCIK, J.: Effect of humidity in the transformer on its safety and reliability (in Slovak), In: ELDICOM 09, Zilina, 2009, pp. 45-47. 